\title{
Experimental Study of Population Variations on the Morphology and Reproduction of Daphnia galeata from Three Chinese Lakes
}

\author{
Yaqin Cao ${ }^{1,2}$, Huiying $\mathrm{Qi}^{1}$, Jun $\mathrm{Li}^{1}$, Kun Zhang ${ }^{1}$, Daogui Deng ${ }^{1,2, \text { * }}$ \\ ${ }^{1}$ School of Life Science, Huaibei Normal University, Huaibei, China \\ ${ }^{2}$ Anhui Key Laboratory of Resource and Plant Biology, School of Life Sciences, Huaibei Normal University, Huaibei, China
}

Email address:

dengdg@chnu.edu.cn (Daogui Deng)

${ }^{*}$ Corresponding author

\section{To cite this article:}

Yaqin Cao, Huiying Qi, Jun Li, Kun Zhang, Daogui Deng. Experimental Study of Population Variations on the Morphology and Reproduction of Daphnia galeata from Three Chinese Lakes. American Journal of Environmental Science and Engineering. Vol. 5, No. 3, 2021, pp. 63-69. doi: 10.11648/j.ajese.20210503.12

Received: July 24, 2021; Accepted: August 11, 2021; Published: August 26, 2021

\begin{abstract}
Environmental heterogeneity affected the genetic differentiation and phenotypic plasticity of Daphnia spp. populations in different lakes. However, the effect mechanism of lake population on the morphology and reproduction of Daphnia spp. was still unclear. This paper studied the differences of the morphology and reproduction of $D$. galeata populations from three Chinese lakes (CH: Lake Chaohu, NH: Lake Nanhu, EH: Lake Erhai), which the area size, nutrient levels, phytoplankton biomass and dominant fish were obviously various in the three lakes. The results showed that lake population affected significantly the morphology (helmet length and tail spine length) and reproduction (no. offspring at first reproduction per female ${ }^{-1}$ ) of $D$. galeata. Both helmet lengths and tail spine lengths of three D. galeata populations increased quickly within the first five instars, and afterwards showed various patterns. Multiple comparisons indicated that helmet lengths of $\mathrm{NH}$ population were significantly higher than those in $\mathrm{EH}$ and $\mathrm{CH}$ populations $(P<0.001)$ whereas tail spine lengths of $\mathrm{NH}$ population were significantly smaller than those in $\mathrm{EH}(P=0.001)$ and $\mathrm{CH}(P=0.003)$ populations. The ratio of relative helmet length of $\mathrm{CH}$ population was significantly shorter than those of $\mathrm{EH}$ population $(P<0.001)$ and $\mathrm{NH}$ population $(P<0.001)$, and the ratio of relative tail spine length at first pregnancy of EH population was significantly longer than those of $\mathrm{CH}$ population $(P<0.001)$ and NH population $(P<0.001)$. Moreover, there is four juvenile instars in EH population whereas there are three juvenile instars in $\mathrm{CH}$ and $\mathrm{NH}$ populations. With the increase of adult instars, the number of offspring produced by $D$. galeata in all three populations displayed a similar pattern, which increased quickly at first, and then gradually decreased. Average maximum number of offspring at first reproduction (6.3 \pm 1.4 ind. per female $\left.\mathrm{e}^{-1}\right)$ appeared in $\mathrm{CH}$ population, followed by $\mathrm{EH}$ (5.2 \pm 1.7 ind. per female $\left.{ }^{-1}\right)$ and $\mathrm{NH}\left(4.9 \pm 1.4\right.$ ind. per female $\left.{ }^{-1}\right)$ populations. The innate rate of increase of $\mathrm{CH}$ population was relatively higher than those of $\mathrm{EH}$ and $\mathrm{NH}$ populations, but no significant differences among three populations were observed. Our results suggested that environmental heterogeneity could affect the reproduction and morphological plasticity of Daphnia spp. in different lakes.
\end{abstract}

Keywords: Daphnia galeata, Morphology, Reproduction, Population, Phenotypic Plasticity

\section{Introduction}

Daphnia are found to distribute widely in inland freshwater [1], and play an important role in the food chain of aquatic ecosystems. Owing to the characteristics of easy culture, fast reproduction and sensitivity to environmental changes $[1,2]$, Daphnia have been utilized in the research fields of evolutionary biology, ecology and environmental toxicology [3, 4]. Usually, Daphnia become dominant zooplankton in lakes because of the abilities of stronger filtering algae and higher fecundity. In order to avoid fish predation, they can be found to induce morphological or reproductive variability in lakes $[5,6]$.

Seasonal dynamics of Daphnia population in lakes is a 
common phenomenon, which is influenced by a variety of environmental factors (e.g. nutrients, predation pressure, food reliability) [7-10]. In lakes, phytoplankton component (such as $\mathrm{N}, \mathrm{P}$ and $\mathrm{C}$ element contents) and structure can be affected by nutrient level [2, 11]. Experimental investigation also showed that nutrient variations in culture medium might cause the change of the nutrient content in phytoplankton [10, 12, 13], and then can lead to the change of Daphnia population density $[7,10,13]$. Daphnia galeata was observed to distribute widely in eutrophic Chinese lakes [4, 14-16]. However, in some mesotrophic or oligotrophic lakes, D. galeata had become dominant species in cladoceras [2, 17]. Our previous investigations indicated that ephippial densities of $D$. galeata were significantly correlated with the nitrogen and phosphorus contents in lake sediments [18- 20]. The predation activity may be other important factor affecting morphological variations and population dynamics of Daphnia. Under the pressure of fish predation, the phenotypic plasticity in the life-history traits and morphology (e.g. Body length, helmet and tail spine) of Daphnia sp. was observed [6, 21-23], and population dynamic of Daphnia sp. were also obviously affected [8]. Moreover, Chaoborus americanus predation induced the reproductive difference and the occurrence of neck teeth of Daphnia pluex [24]. However, under experimental conditions, few studies of the morphology and reproduction of Daphnia populations from different environmental lakes had been reported.

Daphnia sp. located in different lakes have occurred the microevolution and genetic differentiation in order to adapt to the habitat environment [4, 25-30]. In a Chinese lake, long-term eutrophication process affected the genetic differentiation of Daphnia similoieds sinensis [31]. Stoks et al. [32] found that fish predation could influence the relationship between the plasticity and rapid evolution of Daphnia magna. In some lakes located in the middle and lower reaches of the Yangtze River, the genetic diversity and genetic differentiation of $D$. galeata was obvious because of geographic isolation [4]. Previous investigations had showed that the life history parameters of Daphnia sp. could be influenced by their genetic diversity and environmental factors [26, 33].

Although many studies on population dynamic and life-history traits of D. galeata from single population have been reported [3, 10, 34-35], the differences on the reproduction and morphology of $D$. galeata from different populations were not well known. In the field, comparative study on morphological variability of $D$. galeata from the lakes of the Todzha Depression (the Bolshi Yenisei River basin) was investigated [5]. In the present study, the experimental study on the morphology and reproduction of $D$. galeata populations from three Chinese lakes, Lake Chaohu (Yangtze River Basin), Lake Nanhu in Huaibei city (Huaihe River Basin) and Lake Erhai (Lancang River Basin), were carried out, in order to reveal the differences and abilities of D. galeata adaptation to the heterogeneity of different environments.

\section{Material and Methods}

\subsection{Experimental Materials}

Scenedesmus obliquus were purchased from the Freshwater Algae Culture Collection of the Institute of Hydrobiology, the Chinese Academy of Sciences, and cultured in the BG11 medium at $(25 \pm 1)^{\circ} \mathrm{C}$ under a illumination intensity of $2500 \mathrm{~lx}$, with a $12 \mathrm{~h}$ : $12 \mathrm{~h}$ light/dark cycle. S. obliquus were collected at the exponential growth period and stored in a refrigerator at $4{ }^{\circ} \mathrm{C}$.

Three D. galeata populations from Lake Erhai (EH), Lake Nanhu $(\mathrm{NH})$ and Lake Chaohu $(\mathrm{CH})$ were employed. In each population, three clones were collected. Three D. galeata clones in EH population were obtained from the different zones of Lake Erhai in Yunnan Province. Three D. galeata clones in $\mathrm{NH}$ and $\mathrm{CH}$ populations were from the hatching of the resting eggs in the sediments of Lake Nanhu and Lake Chaohu, respectively. All D. galeata clones were fed on $S$. obliquus, and were cultured at $(25 \pm 1)^{\circ} \mathrm{C}$ under a illumination intensity of $2500 \mathrm{~lx}$, with a $12 \mathrm{~h}: 12 \mathrm{~h} \mathrm{light/dark}$ cycle. The neonates at third generation of all $D$. galeata clones were used as the experimental animals (Birth time $<6 \mathrm{~h}$ ). Lake Erhai, Lake Chaohu and Lake Nanhu belong to the Lancang River Basin, the Yangtze River Basin and the Huaihe River Basin in China, respectively. The environmental characteristics of the three lakes are shown in Table 1.

Table 1. Environmental factors in the three lakes.

\begin{tabular}{|c|c|c|c|}
\hline & $\mathbf{E H}$ & CH & NH \\
\hline Total nitrogen $\left(\mathrm{mg} \mathrm{L}^{-1}\right)$ & $0.26-0.93(0.63)$ & $0.92-6.09(3.46)$ & $0.13-1.41(0.56)$ \\
\hline Total phosphorus $\left(\mathrm{mg} \mathrm{L}^{-1}\right)$ & $0.016-0.042(0.03)$ & $0.052-0.215(0.120)$ & $0.02-0.13(0.06)$ \\
\hline Phytoplankton biomass $\left(\mathrm{mg} \mathrm{L}^{-1}\right)$ & $0.68-3.25$ & $5.05-19.70$ & $0.37-5.04(1.99)$ \\
\hline Dominant fish & (Neosalanx tangkahkeii Taihuensis) & $\begin{array}{l}\text { (Coilia ectenes) } \\
\text { (N. tangkahkeii taihuensis) }\end{array}$ & $\begin{array}{l}\text { (Aristichthys nobilis) } \\
\text { (Hypophthalmichthys molitrix) }\end{array}$ \\
\hline Dominant cladoceran species & $\begin{array}{l}\text { (Bosmina coregoni) }(\text { D. galeata }) \\
(\text { Ceriodaphnia quadrangula })\end{array}$ & $\begin{array}{l}\text { (B. coregoni) (Ceriodaphnia } \\
\text { cornuta) }\end{array}$ & $\begin{array}{l}\text { (Bosmina } \mathrm{sp} \text {.) (Diaphanosoma } \\
\text { brachyurum) }\end{array}$ \\
\hline
\end{tabular}

\subsection{Experimental Design}

In the present study, three D. galeata clones in each population were respectively incubated. Fifteen individuals from third generation neonates (birth time $<6 \mathrm{~h}$ ) in each clone were employed. A total of forty-five individuals were used as experimental animals in each population, and each of them was respectively placed in a $50 \mathrm{ml}$ beaker, with $40 \mathrm{ml}$ culture medium which was from filtered tap water (aerated over 48 
h). S. obliquus with a concentration of $2 \times 10^{5}$ cells $\mathrm{ml}^{-1}$ was used as the food of $D$. galeata. The experiment was conducted in a constant temperature illumination incubator at $(25 \pm 1)^{\circ} \mathrm{C}$, with a $12 \mathrm{~h}: 12 \mathrm{~h}$ light/dark cycle and a light intensity of $2500 \mathrm{~lx}$. During the experiment, the culture medium was changed each day and the experiment lasted until all experimental animals died out. Number of offspring at each adult instar (including number of offspring at first reproduction) and innate rate of increase of $D$. galeata were recorded or calculated. All larvae produced by experimental animals were timely removed from the beaker during the experiment. Body length, helmet length and tail spine length of D. galeata were measured in a microscope (Olympus, CX21). Ratio of relative helmet length (helmet length/body length) and relative tail spine length (tail spine length/body length) were calculated.

The formula of innate rate of increase $\left(r_{m}\right)$ is:

$$
\sum_{i=1}^{\mathrm{n}} l_{x} m_{x} e^{-r x}=1
$$

in which $\mathrm{x}$ is the experimental day, $\mathrm{l}_{\mathrm{x}}$ is the survival rate at the specific day, and $m_{x}$ is the fecundity at the specific day.

\subsection{Data Analysis}

SPSS 20.0 software was used to analyze the experimental

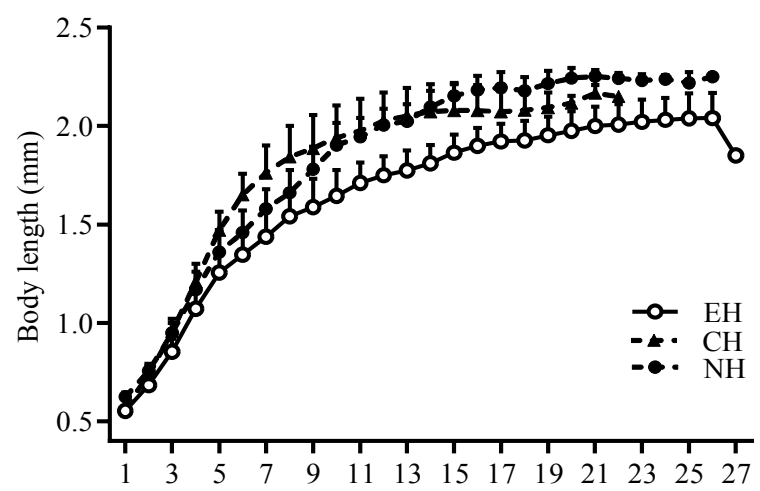

data. One-way ANOVA was used to analyze the effects of population on the morphological and reproductive parameters of D. galeata, and multiple comparisons (Tukey HSD) were employed to detect their differences among different populations. Statistical data are transformed through $\ln (\mathrm{x}+1)$.

\section{Results}

Body lengths of three D. galeata (Sars) populations increased all gradually with the increase of instar number (Figure 1). Body lengths of EH population were shorter than those of $\mathrm{CH}$ and $\mathrm{NH}$ populations, but there were no significant differences among three populations.

Helmet lengths of all three D. galeata populations showed a quickly increasing trend within the first five instars, and then displayed different patterns after the sixth instar (Figure 1). The effect of population on helmet length of D. galeata was significant $(\mathrm{F}=62.944, P<0.001)$ as well as helmet length at first pregnancy. Multiple comparisons Tukey HSD showed that Helmet length of $\mathrm{NH}$ population was significantly longer than those of $\mathrm{EH}$ and $\mathrm{CH}$ populations $(P<0.001)$ as well as helmet length at first pregnancy (Table 2), and helmet length of EH population was significantly longer than that of $\mathrm{CH}$ population $(P<0.001)$.

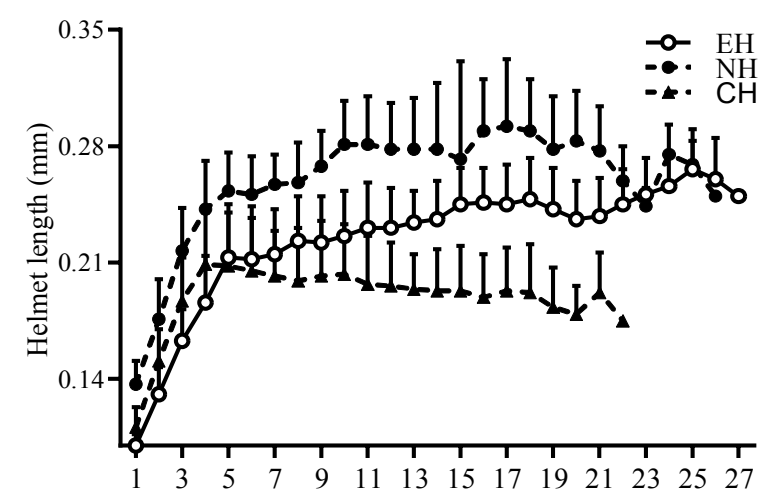

$\begin{array}{ll}-0- & \mathrm{EH} \\ -\bullet \cdot & \mathrm{CH} \\ -\bullet & \mathrm{NH}\end{array}$

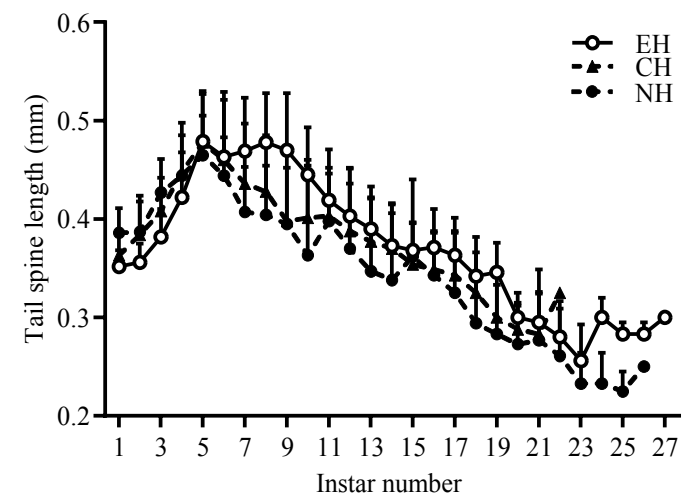

Figure 1. Changes of body length, helmet length and tail spine length in three D. galeata populations.

Tail spine lengths of all three D. galeata populations showed a quickly increasing trend within the first five instars, and then dropped gradually (Figure 1). The effects of population $(F=8.410, P<0.001)$ on the tail spine length of $D$. galeata were significant. Tail spine length of NH population was significantly shorter than those of $\mathrm{CH}(P=0.003)$ and $\mathrm{EH}$ $(P=0.001)$ populations. There were no significant differences in tail spine lengths at first pregnancy of $D$. galeata among 
three populations (Table 2).

Table 2. Morphological and reproductive parameters of three D. galeata populations.

\begin{tabular}{llll}
\hline Parameters & EH & CH & NH \\
\hline Body length at first pregnancy (mm) & $1.26 \pm 0.05$ & $1.42 \pm 0.11$ & $1.34 \pm 0.04$ \\
Helmet length at first pregnancy (mm) & $0.21 \pm 0.02$ & $0.21 \pm 0.01$ & $0.25 \pm 0.01$ \\
Tail spine length at first pregnancy (mm) & $0.48 \pm 0.03$ & $0.47 \pm 0.03$ & $0.46 \pm 0.03$ \\
No. offspring at first reproduction (ind. per female ${ }^{-1}$ ) & $5.2 \pm 1.7$ & $6.3 \pm 1.4$ & $4.9 \pm 1.4$ \\
\hline
\end{tabular}

With the increase of adult instars, the number of offspring produced by $D$. galeata in all three populations displayed a similar pattern, which increased quickly at first, and then gradually decreased (Figure 2). The mean maximum (16.4 ind. per female ${ }^{-1}$ ) appeared in the $16^{\text {th }}$ instar in $\mathrm{NH}$ population. The influence of population on number of offspring at first reproduction of $D$. galeata was significant $(\mathrm{F}=3.111, P=0.048)$, but it was no significant effect on number of offspring of $D$. galeata $(\mathrm{F}=2.769, P=0.066)$. Average maximum number of offspring at first reproduction $\left(6.3 \pm 1.4\right.$ ind. per female $\left.{ }^{-1}\right)$ appeared in $\mathrm{CH}$ population, followed by EH $\left(5.2 \pm 1.7\right.$ ind. per female $\left.{ }^{-1}\right)$ and $\mathrm{NH}(4.9 \pm 1.4$ ind. per female ${ }^{-1}$ ) populations (Table 2). Moreover, there is four juvenile instars in EH population whereas three are three juvenile instars in $\mathrm{CH}$ and $\mathrm{NH}$ populations.

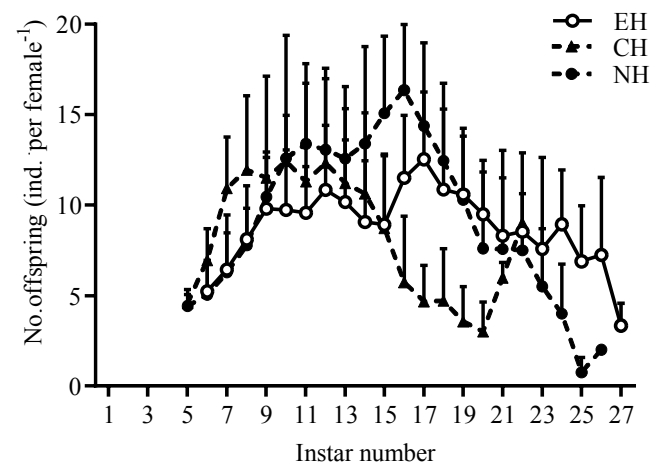

Figure 2. Changes of number of offspring produced by per female in three D. galeata populations.

The innate rate of increase of $D$. galeata in $\mathrm{CH}$ population was relatively higher than those in $\mathrm{EH}$ and $\mathrm{NH}$ populations (Figure 3). Multiple comparisons (Tukey HSD) indicated that no significant differences in the innate rate of increase of $D$. galeata among three populations were observed $(P>0.05)$.

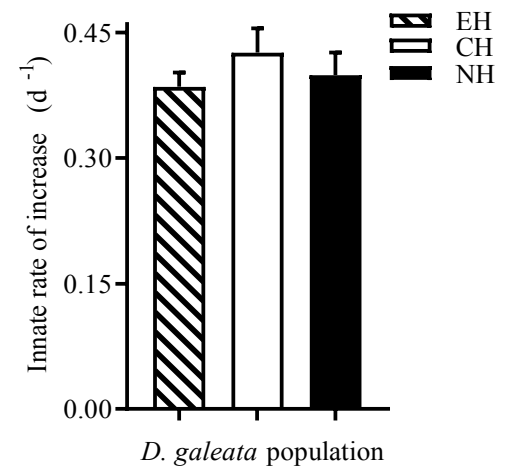

Figure 3. Changes of the innate rate of increase $\left(r_{m}\right)$ in three D. galeata populations.
Ratio of relative helmet lengths of all three $D$. galeata populations declined gradually except within the first two instars (Figure 4). The effect of population on the ratio of relative helmet lengths of $D$. galeata was significant $(\mathrm{F}=18.502, P<0.001)$ as well as the ratio of relative helmet lengths at first pregnancy $(\mathrm{F}=41.689, P<0.001)$. Multiple comparisons (Tukey HSD) indicated that there were all significant differences in the ratio of relative helmet lengths of $D$. galeata among three populations $(P<0.001)$, and the ratio of relative helmet lengths of $\mathrm{CH}$ population was significantly shorter than those of EH population $(P<0.001)$ and $\mathrm{NH}$ population $(P<0.001)$.

Ratio of relative tail spine lengths of all three $D$. galeata populations declined gradually (Figure 4). There was a significant effect of population on the ratio of relative tail spine lengths at first pregnancy of D. galeata $(\mathrm{F}=15.231$, $P<0.001$ ). Multiple comparisons (Tukey HSD) indicated that the ratio of relative tail spine lengths at first pregnancy of $\mathrm{EH}$ population was significantly longer than those of $\mathrm{CH}$ population $(P<0.001)$ and $\mathrm{NH}$ population $(P<0.001)$.
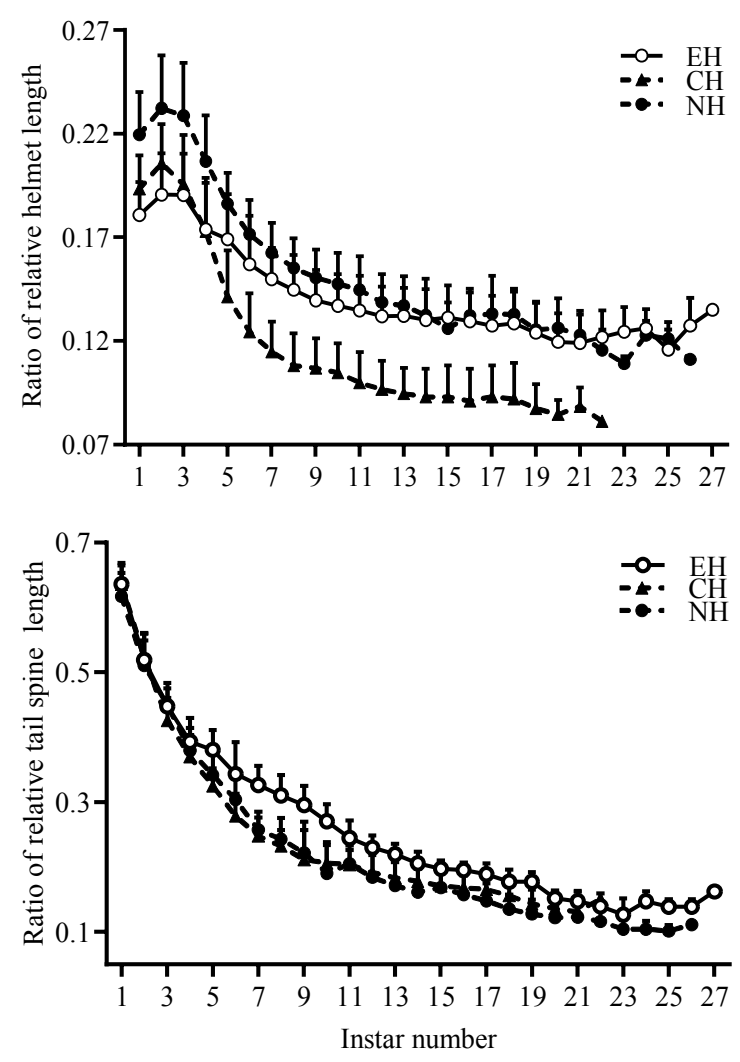

Figure 4. Changes of the relative helmet length and tail spine length in three D. galeata populations. 


\section{Discussion}

In general, the phenotypic plasticity of aquatic organisms can be induced in order to adapt to rapid changes of biotic and abiotic factors [38]. Previous studies have shown that cladocera can transfer the information of the mothers obtaining from local environment to their offspring through maternal effects [39-41], so that their offspring showed more adaptation to similar environment [42]. Usually, Daphnia sp. has undergone the alternation of generations in a lake. Therefore, the morphological and reproductive parameters of Daphnia sp. from different lakes obtained in the experiment could reveal their response to environmental pressures in their habitats to some extent.

Many studies have shown that the predation pressure can lead to the occurrence of phenotypic plasticity of prey [43-45], including the change in morphology of Daphnia sp. [22-24, 46]. Weber and Vesela [46] found that the pheromone of perch affected significantly the helmet lengths of different D. galeata clones [22]. Tilapia-mediated water enhanced tail spine lengths in Daphnia laevis and Daphnia similis clones. Tams et al. [23] observed intraspecific phenotypic differences in body length and life-history traits of four D. galeata populations under fish kairomones. Moreover, in the presence of invertebrate predator, the predation of $C$. americanus induced the occurrence of neck teeth of D. pulex [24]. In the field, Zuykova and Bochkarev [5] found that highly morphological variability (such as helmet and spine length) of $D$. galeata in the lakes of the Todzha Depression varied markedly among populations, depending on the environmental conditions. In the present study, the helmet lengths of $D$. galeata in $\mathrm{NH}$ population were significantly longer than those in $\mathrm{EH}$ and $\mathrm{CH}$ populations as well as helmet lengths at first pregnancy, whereas the tail spine lengths of $\mathrm{NH}$ population were significantly shorter than those of $\mathrm{EH}$ and $\mathrm{CH}$ populations. Moreover, the effects of population on the ratios of relative helmet lengths and relative tail spine lengths at first pregnancy of $D$. galeata were all significant. The dominant species of fish in the three lakes were different to some extent (Table 1), and this may be one of the reasons to cause the differences on the helmet length and tail spine length of three $D$. galeata populations in the present study. In some Chinese lakes, the individuals of $D$. similodies sinensis from lakes in the presence of fish showed significantly shorter body lengths and prominent recurvate helmets compared with the individuals from fishless lakes [6]. Therefore, the presence of predator could induce the intraspecific variation of Daphnia, and then lead to phenotypic plasticity and improve their adaptability to the environment.

Usually, the innate rates of increase of Daphnia sp. are affected by nutrient level, food reliability and fish predation $[12,47-48]$. In eutrophic lake, Lake Dongdu, the innate rate of increase of D. galeata was 0.46 ind. $\mathrm{d}^{-1}$ [47]. Weers and Gulati [12] found that D. galeata fed P-limited alga deceased obviously their growth and reproduction (e.g. the innate rate of increase). In the present study, the innate rates of increase of D. galeata were respectively 0.40 ind. $\mathrm{d}^{-1}$ in Lake Nanhu (mesotrophic), 0.39 ind. $\mathrm{d}^{-1}$ in Lake Erhai (mesotrophic), and 0.43 ind. $\mathrm{d}^{-1}$ in Lake Chaohu (eutrophic). Repka [48] also reported that the innate rates of increase of Daphnia sp. from different nutrient lakes had greater differences. In general, higher nutrient level favored the increase of edible phytoplankton biomass, and then improved population densities of Daphnia sp. [8]. Moreover, Tolardo et al. [22] found that fish-mediated water enhanced intrinsic rates of population increase (r) in D. laevis and D. similis clones. Therefore, the heterogenicity of the three lakes in nutrient level, phytoplankton biomass and fish predation might affect the reproductive ability of $D$. galeata together in the present study.

\section{Conclusions}

Environmental heterogeneity affected the genetic differentiation and phenotypic plasticity of Daphnia spp. populations in different lakes. In the present study, the differences of the morphology and reproduction of $D$. galeata populations from three Chinese lakes $(\mathrm{CH}$ : Lake Chaohu, $\mathrm{NH}$ : Lake Nanhu, EH: Lake Erhai) were studied. The area size, nutritive levels, phytoplankton biomass and dominant fish of the three lakes were obviously various. Our results showed that lake population affected significantly the morphology (helmet length and tail spine length) and reproduction (no. offspring at first reproduction per female ${ }^{-1}$ ) of D. galeata. Both helmet lengths and tail spine lengths of three D. galeata populations increased quickly within the first five instars, and afterwards showed various patterns. Multiple comparisons showed that helmet lengths of $D$. galeata $\mathrm{NH}$ population were significantly higher than those in $\mathrm{EH}$ and $\mathrm{CH}$ populations whereas tail spine lengths of D. galeata $\mathrm{NH}$ population were significantly smaller than those in EH and $\mathrm{CH}$ populations. Moreover, the significant effects of population on the ratios of relative helmet and relative tail spine length at first pregnancy of $D$. galeata were also all observed. With the increase of adult instars, the number of offspring produced by $D$. galeata in all three populations displayed a similar pattern, which increased quickly at first, and then gradually decreased. Average maximum number of offspring at first reproduction appeared in $\mathrm{CH}$ population, followed by $\mathrm{EH}$ and $\mathrm{NH}$ populations. In addition, the innate rate of increase of $\mathrm{CH}$ population was relatively higher than those of $\mathrm{EH}$ and $\mathrm{NH}$ populations, but no significant differences among three populations were observed. Our results suggested that environmental heterogeneity could affect the reproduction and morphological plasticity of Daphnia spp. in different lakes.

\section{Acknowledgements}

This work was supported by grants from the National Natural Science Foundation of China (Grant Numbers 31870451 and 31370470). 


\section{References}

[1] Benzie, J. A. H. (2005). The genus Daphnia (including Daphniopsis) (Anomopoda: Daphniidae) (In: [Dumont HJF] Ed: Guides to the identification of the microinvertebrates of the continental waters of the world 21) - Leiden, Backhuys Publishers, 172-176.

[2] Hartwich, M., Martin-Creuzburg, D., Rothhaupt, K. O., \& Wacker, A. (2012). Oligotrophication of a large, deep lake alters food quantity and quality constraints at the primary producer-consumer interface. Oikos, 121 (10), 1702-1712.

[3] Cui, R. X., Kwak, J. Il, \& An Y. J. (2018). Comparative study of the sensitivity of Daphnia galeata and Daphnia magna to heavy metals. Ecotoxicology and Environmental Safety, 162 (1), 63-70.

[4] Liu, Q., Deng, D. G., Zhang, K., He, P., Sun, Y. C., Zhang, T. T., Yang, W., \& Liu, W. (2019). Genetic diversity and differentiation of Daphnia galeata in the middle and lower reaches of the Yangtze River, China. Ecology and Evolution, 9 (22), 12688-12700.

[5] Zuykova, E. I., \& Bochkarev, N. A. (2011). Population morphological variability of the Daphnia galeata populations (Cladocera: Anomopoda) in the lakes of the Todzha depression. Russian Journal of Ecology, 42 (4), 296-304.

[6] Ma, X., Wolinska, J., Petrusek, A., Gie ler, S., Hu, W., \& Yin, M. (2019). The phenotypic plasticity in Chinese populations of Daphnia similoides sinensis: recurvate helmeted forms are associated with the presence of predators. Journal of Plankton Research, 38 (4), 855-864.

[7] Sommer, U., Gliwicz, Z. M., Lampert, W., \& Duncan, A. (1986). The PEG model of seasonal succession of planktonic events in fresh waters. Archiv für Hydrobiologie, 106 (4), 433-471.

[8] Deng, D. G., Xie, P., Zhou, Q., Yang, H., Guo, L. G., \& Geng, H. (2008). Field and experimental studies on the combined impacts of cyanobacterial blooms and small algae on crustacean zooplankton in a large, eutrophic subtropical Chinese lake. Limnology, 9 (1), 1-11.

[9] Prater, C., Wagner, N. D., \& Frost P. C. (2017). Interactive effects of genotype and food quality on consumer growth rate and elemental content. Ecology, 98 (5), 1399-1408.

[10] Ming, R. L., Liu, R. Q., \& Lin, Q. Q. (2019). Effect of food quality (C: $\mathrm{P}$ ratio) and interspecific competition on population growth of Daphnia galeata and Bosmina fatalis. Journal of Lake Sciences, 31 (1), 211-219 (in Chinese).

[11] Elser, J. J., Bracken, M. E. S., Cleland, E. E., Gruner, D. S., Harpole, W. S., Hillebrand, H., Ngai, J. T., Seabloom, E. W., Shurin, J. B., \& Smith, J. E. (2007). Global analysis of nitrogen and phosphorus limitation of primary producers in freshwater, marine and terrestrial ecosystems. Ecology Letters, 10 (12), 1135-1142.

[12] Weers, P. M. M., \& Gulati, R. D. (1997). Growth and reproduction of Daphnia galeata in response to changes in fatty acids, phosphorus, and nitrogen in Chlamydomonas reinhardtii. Limnology and Oceanography, 42 (7), 1584 -1589.

[13] Meng, M. R., Deng, D. G., Zhang, X. L., Ge, Q., \& Zhang, K. (2014). The influence of different phosphorus concentrations on the population dynamics and resting egg formation of two cladocerans. Journal of Freshwater Ecology, 29 (3), 387-396.

[14] Deng, D. G., Meng, Q., Yin, S. T., Feng, N. S., \& Xiao, Q. Q. (2008). Effect of temperature and food concentration on population dynamic and sexual reproduction of Daphnia magna. Acta Ecologica Sinica, 28 (9), 4268-4276 (in Chinese).

[15] Ma, X., Petrusek, A., Wolinska, J., Giebler, S., Zhong, Y., Yang, Z., Hu, W., \& Yin, M. (2015). Diversity of the Daphnia longispina species complex in Chinese lakes: A DNA taxonomy approach. Journal of Plankton Research. 37 (1), 56-65.

[16] Ma, X., Hu, W., Smilauer, P., Yin, M., \& Wolinska, J. (2019). Daphnia galeata and D. dentifera are geographically and ecologically separated whereas their hybrids occur in intermediate habitats: a survey of 44 Chinese lakes. Molecular Ecology, 28 (4), 785-802.

[17] Yang, W., Deng, D. G., Zhang, S., \& Hu, C. L. (2014). Seasonal dynamics of community structure of crustacean zooplankton in Erhai Lake, a plateau lake, with reference to phytoplankton and environmental factors. Chinese Journal of Oceanology and Limnology, 32 (5), 1074-1082.

[18] He, P., Zhang, K., Deng, D. G., Liu, Q., Guo, H. H., Zhang, T. T., \& Sun Y. C. (2018). Vertical distribution of Daphnia ephippia and its correlation with total nitrogen and total phosphorus in the sediments of Meiliang Bay in Lake Taihu. Chinese Journal of Ecology, 37 (8), 2411-2417 (in Chinese).

[19] Liu, Q., H, e P., Peng, S. X., Zhang, T. T., Sun, Y. C., \& Deng D. G. (2018). Long-term changes of ephippial densities of Daphnia species in the sediment of isolated lakes of Poyang Lake - Junshan Lake and its correlation with the nutrients. Journal of Lake Science, 30 (5), 1388-1399 (in Chinese).

[20] Zhang, K., Deng, D. G., Wang, W. P., Peng, S. X., Liu, F., \& Ji, L. (2020). Long-term eutrophication affects vertical changes of Daphnia ephippia in the sediments of a subtropical Chinese lake. Evironmental Science and Pollution Research. 27 (5), 4737-4745.

[21] Boersma, M., Spaak, P., \& De Meester, L. (1998). Predator-mediated plasticity in morphology, life history, and behavior of Daphnia: the uncoupling of responses. The American Naturalist, 152 (2), 237-248.

[22] Tolardo, M., da, Silva, Ferrão-Filho, A., \& Santagelo, J. M. (2016). Species and clone-dependent effects of tilapia fish (Cichlidae) on the morphology and life-history of temperate and tropical Daphnia. Ecological Research, 31 (3), 333-342.

[23] Tams, V., Lüneburg, J., Seddar, L., Detampel, J. P., \& Cordellier, M. (2018). Intraspecific phenotypic variation in life history traits of Daphnia galeata populations in response to fish kairomones. Peer J, 6, e5746.

[24] Spitze, K. (1992). Predator-mediated plasticity of prey life history and morphology: Chaoborus americanus predation on Daphnia pulex. The American Naturalist, 139 (2), 229-247.

[25] Weider, L. J., \& Hebert P. D. N. (1987). Ecological and physiological differentiation among low-arctic clones of Daphnia pulex. Ecology, 68 (1), 188-198.

[26] Antunes, S. C., Castro, B. B, \& Gonçalves, F. (2003). Chronic responses of different clones of Daphnia longispina (field and ephippia) to different food levels. Acta Oecologica, 24 (1), 325-332. 
[27] Davidson, A. M., Jennions, M., Nicotra, A. B. (2011). Do invasive species show higher phenotypic plasticity than native species and, if so, is it adaptive? A meta-analysis. Ecology Letters, 14 (4), 419-431.

[28] Wang, W. P., Zhang, K., Deng, D. G., Zhang, Y. N., Peng, S. X., \& Xu, X. X. (2016). Genetic diversity of Daphnia pulex in the middle and lower reaches of the Yangtze River. Plos One, 11 , e0152436.

[29] Tokishita, S., Shibuya, H., Kobyashi, T., Sakamoto, M., Ha, J. Y., Yokobori, S., Yamagata, H., \& Hanazato, T. (2017). Diversification of mitochondrial genome of Daphnia galeata (Cladocera, Crustacea): comparison with phylogenetic consideration of the complete sequences of clones isolated from five lakes in Japan. Gene, 611, 38-46.

[30] Wu, J. X., Wang, W. P., Deng, D. G., Zhang, K., Peng, S. X., Xu, X. X., Zhang, Y. N., \& Zhou, Z. Z. (2019). Genetic diversity and phylogeography of Daphnia similoides sinensis located in the middle and lower reaches of the Yangtze River. Ecology and Evolution, 9 (8), 4362-4372.

[31] Wu, J. X., Zhang, K., Deng, D. G., Liu, Q., Peng, S. X., Zhang, T. T., \& Zhou, Z. Z. (2019). Effects of rapid enclosure of aquatic ecosystems on genetic diversity and genetic structure of Daphnia similoides sinensis in a eutrophic Chinese lake. Russian Journal of Ecology, 50 (3), 289-299.

[32] Stoks, R., Govaert, L., Pauwels, K., Jansen, B., \& De, Meester, L. (2016). Resurrecting complexity: the interplay of plasticity and rapid evolution in the multiple trait response to strong changes in predation pressure in the water flea Daphnia magna. Ecology Letters, 19 (2), 180-190.

[33] Harney, E., Paterson, S., \& Plaistow, S. J. (2017). Offspring development and life-history variation in a water flea depends upon clone-specific integration of genetic, non-genetic and environmental cues. Functional Ecology, 31 (10), 1996-2007.

[34] Huang, C., Liu, Q. G., Hu, Z. J., Hou, W. H., Wu, J. Y., He, G. X., \& Chen, L. S. (2014). Effects of different algae as food on growth of water fleas Daphnia hyalina. Journal of Dalian Ocean University. 29 (2), 131-135 (in Chinese).

[35] Huang, X. F., Zhang, X. L., Franja, P., \& Han, B. P. (2017). Growth and reproduction of two Daphnia species (D. sinensis and D. galeata) in tropics at five levels of food concentrations. Chinese Journal of Applied and Environmental Biology, 23 (6), 1148-1153 (in Chinese).

[36] Yang, W., Deng, D. G., Meng, X. L., \& Zhang, S. (2019) Temporal and spatial variations of phytoplankton community structure in Lake Erhai, a Chinese plateau lake, with reference to environmental factors. Russian Journal of Ecology, 50 (4), 352-360.

[37] Deng, D. G., Xing, R. L., Ma, R., Zhang, S., Meng, X. L., \&
Yang, W. (2010). Seasonal variations on community structure of crustacean zooplankton in a small lake of an excavating coal subsidence region in Huaibei City. Journal of Lake Sciences, 22 (4), 591-597 (in Chinese).

[38] Hendry, A. P., Farrugia, T. J., \& Kinnison, M. T. (2008). Human influences on rates of phenotypic change in wild animal populations. Molecular Ecology, 17 (1), 20-29.

[39] Gustafsson, S., Rengefors, K., Hansson, L. A. (2005). Increased consumer fitness following transfer of toxin tolerance to offspring via maternal effects. Ecology, 86 (10), 2561-2567.

[40] Walsh, M. R., Castoe, T., Holmes, J., Packer, M., Biles, K., Walsh, M., Munch, S. B., \& Post, D. M. (2016). Local adaptation in transgenerational responses to predators. Proceedings of the Royal Society B: Biological Sciences, 283 (1823), 20152271.

[41] Radersma, R., Hegg, A., Noble, D. W. A., \& Uller, T. (2018). Timing of maternal exposure to toxic cyanobacteria and offspring fitness in Daphnia magna: implications for the evolution of anticipatory maternal effects. Ecology and Evolution, 8 (24), 12727-12736.

[42] Rinke, K., Hülsmann, S., \& Mooij, W. M. (2008). Energetic costs, underlying resource allocation patterns, and adaptive value of predator-induced life-history shifts. Oikos, 117 (2), 273-285.

[43] Larsson, P., \& Dodson, S. I. (1993). Invited review: chemical communication in planktonic animals. Archiv fur Hydrobiologie, 129 (2), 129-155.

[44] Ke, Z., \& Huang, L. (2009). Advance in the study on the anti-predator phenotypic plasticity of Daphnia. Journal of Lake Sciences, 21 (6), 758-767 (in Chinese).

[45] Alexander, T. J., Vonlanthen, P., \& Seehausen, O. (2017). Does eutrophication-driven evolution change aquatic ecosystems? Philosophical transactions of the Royal Society of London. Series B, Biological sciences, 372 (1712), 20160041.

[46] Weber, A., \& Vesela, S. (2002). Optimising survival under predation: chemical cues modify curvature in Daphnia galeata. Aquatic Ecology, 36 (4), 519-527.

[47] Huang, X. (1984). Effect of temperature on development and growth of Daphnia hyalina and Daphnia carinata ssp. (Cladocera: Daphniadae). Acta Hydrobiologica Sinica, 8 (2), 207-224 (in Chinese).

[48] Repka, S. (1997). Effects of food type on the life history of Daphnia clones from lakes differing in trophic state. Freshwater biology, 38 (3), 675-683. 